
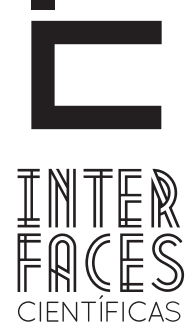

DIREITO

ISSN IMPRESSO 2316-3321

E - ISSN 2316-381X

DOI - 10.17564/2316-381X.2019v7n1p69-80

DOSSIÊ “30 ANOS DA CONSTITUIÇÃO FEDERAL: GANHOS, PERDAS E DESAFIOS EM MATÉRIA DE DIREITOS HUMANOS".

\title{
O MARCO DA CONSTITUIÇÃO DE 1988 NA HISTÓRIA DOS DIREITOS TRABALHISTAS DAS EMPREGADAS DOMÉSTICAS NO BRASIL
}

\author{
THE FRAMEWORK OF THE CONSTITUTION OF THE 1988 IN THE HISTORY OF LABOR RIGHTS OF DOMESTIC IN BRAZIL
}

EL MARCO DE LA CONSTITUCIÓN DE 1988 EN LA HISTORIA DE LOS DERECHOS DE LAS EMPLEADAS DOMÉSTICAS EN BRASIL

Jeferson de Jesus Nicácio ${ }^{1}$

\section{RESUMO}

0 presente artigo visa discutir o significado do marco da Constituição Federal de 1988 no que diz respeito aos direitos das trabalhadoras domésticas no Brasil. A partir da relação que buscamos estabelecer entre a luta política dessas trabalhadoras e o contexto histórico em que tal processo constituinte ocorreu, refletiremos a respeito das tensões, contradições e potencialidades existentes a partir do marco constitucional. Como metodologia, faremos um estudo interdisciplinar e sociojurídico das leis estabelecidas para a regulação do emprego doméstico no contexto em que foram concebidas e implementadas, em diálogo com a bibliografia especializada a respeito dos processos sociais de cada momento histórico refleti- dos pela sociologia do trabalho. 0 método utilizado foi a análise de conteúdo (BARDIN, 2006) da legislação concernente ao tema, do material documental produzido pelas próprias trabalhadoras a respeito do processo - principalmente seus depoimentos - e das referências bibliográficas sobre a história do Brasil em geral e do processo de lutas das trabalhadoras domésticas neste período.

\section{PALAVRAS-CHAVE}

Constituição de 1988. Trabalhadoras Domésticas. Direitos trabalhistas. 


\section{ABSTRACT}

This article aims to discuss the meaning of the framework of the Federal Constitution of 1988 regarding the rights of domestic workers in Brazil. From the relationship we seek to establish between the political struggle of these workers and the historical context in which this constituent process occurred, we will reflect on the tensions, contradictions and potentialities existing from the constitutional framework. As a methodology, we will make an interdisciplinary study and legal partner of the established laws for the regulation of domestic employment in the context in which they were conceived and implemented, in dialogue with the specialized bibliography regarding the

\section{RESUMEN}

El presente artículo apunta a discutir el significado del marco de la Constitución Federal de 1988 en lo que se refiere a los derechos de las trabajadoras domésticas en Brasil. A partir de la relación que buscamos establecer entre la lucha política de esas trabajadoras y el contexto histórico en que ocurrió ese proceso constituyente, reflexionamos acerca de las tensiones, contradicciones y potencialidades existentes a partir del marco constitucional. Como metodología, haremos un estudio interdisciplinario y socio jurídico de las leyes establecidas para la regulación del empleo doméstico en el contexto en que fueron concebidas e implementadas, en diálogo con la bibliografía especializada acerca de los procesos socia- social processes of each historical moment reflected by the sociology of work. The method used was the content analysis of the legislation regarding the subject, the documentary material produced by the workers themselves regarding the process - mainly their testimonies - and the bibliographical references about the history of Brazil in general and the process of struggles of domestic workers in this period.

\section{KEYWORDS}

Brazilian Constitution of 1988. Domestic workers. Labor rights.

les de cada momento histórico reflejados por la sociología del trabajo. El método utilizado fue el análisis de contenido de la legislación concerniente al tema, del material documental producido por las propias trabajadoras acerca del proceso - principalmente sus testimonios - y de las referencias bibliográficas sobre la historia del Brasil en general y del proceso de luchas de las trabajadoras domésticas en este período.

\section{PALABRAS CLAVE}

Constitución de 1988. Trabajadoras domésticas. Derechos laborales. 


\section{INTRODUCÇÃO}

0 movimento das trabalhadoras domésticas remonta a 1936, data da fundação da primeira Associação das Empregadas Domésticas do Brasil. A associação foi fechada logo depois, em decorrência das restrições impostas durante a ditadura de Getúlio Vargas, reabrindo apenas em 1946. Desde o início, o movimento buscou a reunião das trabalhadoras domésticas a fim de pautar os direitos trabalhistas da categoria: primeiro o seu reconhecimento profissional, depois pela equiparação em relação aos demais setores da classe obreira (BERNADINO-COSTA, 2007).

A partir da década de 1980, uma frente nacional feita pelas diferentes associações espalhadas pelo Brasil inicia uma participação no processo de redemocratização articulada a outros movimentos sociais e políticos (partidos, movimento negro, movimento feminista), a fim de atuar na Constituinte. Então, as domésticas passam a integrar diversas caravanas realizadas à Brasília no intuito de pressionar os parlamentares para que estes incorporassem a categoria no capítulo dos direitos sociais e garantissem demandas trabalhistas tal qual eram garantidas a outras categorias.

Faremos, em primeiro lugar, levando esse cenário em consideração, uma discussão sobre o contexto de transição democrática no qual se deu o processo que culminou na Constituinte. Em seguida, analisaremos os direitos das domésticas garantidos na Constituição Federal (CF) de 1988 e seus desdobramentos, tanto do ponto de vista das suas limitações, quanto a respeito daquilo que potencializou e/ou possibilitou avançar nas lutas que foram empreendidas pelas domésticas ao fazer recurso dos princípios estabelecidos pela própria Carta Magna.

\section{CONTEXTO DE TRANSIÇÃO DEMOCRÁTICA}

A historiografia costuma denominar de "transição democrática" o período que se deu após a revogação de instrumento de exceção no final de 1978, entrando em vigência a partir de janeiro de 1979, até 1988 (ALENCAR, 1994). Nesse momento, se não havia se estabelecido ainda um regime democrático, também não se considera razoável dizer que a sociedade brasileira vivia sob uma ditadura militar tal como ela se estruturou nos chamados "anos de chumbo", entre 1968 e 1974.

Resistia um entulho autoritário expresso na legislação social e política do país, contudo não havia um estado de exceção, isto é, o arbítrio exercício da vontade dos governantes dirigentes por meio da edição, revogação ou desconsideração de leis a disciplinar cada comportamento dos cidadãos. 0 fim do regime militar havia tornado necessário o reordenamento jurídico do país e a feitura de uma nova Constituição. A carta em vigor, de 1967, acrescida do "emendão" de 1969 e outras alterações impostas pela ditadura, era a forma acabada do "entulho autoritário". Havia um consenso de que este velho ordenamento jurídico-político-institucional precisava ser removido.

A convocação da Assembleia Nacional Constituinte Livre e Soberana já era parte das demandas do movimento de oposição democrática militar desde meados dos anos 1970, em que pese o Congresso Constituinte instaurado acabou por refletir "as limitações e o caráter pactuado da transição democrática" (ABRAMO, 2010). Diversas forças dos movimentos sociais de toda ordem organizavam-se não apenas a fim de discutir os princípios gerais que deveriam nortear a nova constituição, mas apresentar propostas ligadas a demandas relacionadas a direitos historicamente negados. Associações, sindicatos e variados segmentos sociais, todos eram animados a repensar o país e suas estruturas, a organização do Estado, a forma política e a propriedade dos meios de produção.

\section{A LUTA DAS DOMÉSTICAS NA CONSTITUINTE}

No dia 15 de novembro de 1986 foram eleitos os constituintes, empossados em $1^{\circ}$ de fevereiro de 1987. Tratava-se de um Congresso Constituinte que tinha dupla atribuição: legislar normalmente como congresso e, ao mesmo tempo, redigir e votar a nova 
Constituição. Dentre eles, havia 23 membros “biônicos”, em virtude de ainda exercerem mandatos no Senado para o qual tinham sido eleitos indiretamente. Além de diversas falhas nos critérios de representatividade (falta de razoável proporcionalidade entre a população dos estados e territórios e o número de seus representantes no Congresso, por exemplo), grande influência do poder econômico - como sempre -; sem contar as desigualdades existentes entre os partidos (os maiores tinham mais tempo de propaganda gratuita na televisão por exemplo). Em suma, todo esse processo resultou num Congresso conservador em sua maioria.

Todavia, todo o trabalho da constituinte foi marcado por uma novidade: a possibilidade de apresentação de propostas populares à elaboração constitucional. TrabaIhadores rurais, operários, funcionários públicos, donas de casa, professores, estudantes e outros segmentos se articularam em torno de algumas ideias e pautas em comum, elaboraram emendas e foram às ruas colher apoios. As elites econômicas também se mobilizaram, apresentando inúmeras propostas, por meio de suas associações representativas. Resultado: 15 milhões de eleitores assinaram mais de 50 emendas populares ao texto básico. Organizadas em grupos de pressão (os lobbies), as elites e uma parcela do povo procuraram legitimamente apresentar propostas e resguardas seus interesses (ALENCAR, 1994; SILVA, 2012).

No interior de um processo de reorganização, fortalecimento sindical e de retomada das negociações coletivas, em decorrência de greves e mobilizações realizadas no final dos anos 1970 , desenvolvia-se o chamado "Novo Sindicalismo", cuja atuação seria bastante importante em todo processo da Constituinte. Inúmeras de suas lideranças, ligadas ao Partido dos Trabalhadores (PT), deram contribuições imprescindíveis nessa fase de discussão a respeito dos rumos da democracia, bem como na própria instauração das instituições democráticas - em que pese não se possa dizer o mesmo nos tempos atuais (ABRAMO, 2010)

Por outro lado, entre os setores mais organizados estavam o movimento de mulheres. Já a partir da criação do Conselho Estadual em 1983 em São Paulo há as primeiras manifestações em torno da luta por construir uma Constituinte soberana. Desse modo, insiste a pesquisadora feminista Salete Maria da Silva (2012, p. 123):

\begin{abstract}
Com atuação junto ao Conselho Nacional dos Direitos da Mulher-CNDM, as mulheres lançaram, em 1985, a campanha Mulher e Constituinte, cujo lema era: "Constituinte prá valer tem que ter palavra de mulher". Esta campanha permitiu que discussões e debates acontecessem entre as mulheres, durante meses, por todo o país, resultando na elaboração da "Carta da Mulher Brasileira aos Constituintes", a qual foi entregue ao Congresso Nacional no dia 26 de agosto de 1986, pelas mãos de mais de mil mulheres, numa atuação que, no processo constituinte, ficou publicamente caracterizada como o "lobby do batom". Esta carta, sistematizadora de reivindicações que foram transformadas em direitos na Constituição Federal, foi o símbolo de todo esse processo, único na história do movimento de mulheres no Brasil. Pode-se dizer, portanto, que as mulheres marcaram a Constituição de 1988, uma vez que cerca de $80 \%$ de suas reivindicações foram incorporadas ao texto constitucional, pois, em face da pressão exercida pela organização e mobilização das mulheres, a Constituição estabeleceu, em seu artigo $5^{\circ}$, inciso I, que "homens e mulheres são iguais em direitos e obrigações", e no inciso XLI deste mesmo artigo, que "a lei punirá qualquer discriminação atentatória aos direitos e liberdades fundamentais.
\end{abstract}

$\mathrm{Na}$ "Carta da Mulher Brasileira aos Constituintes" encontra-se uma série de reivindicações sobre diversas dimensões dos direitos sociais e trabalhistas, além de se propugnar por princípios gerais que deveriam nortear a Constituição no sentido de efetivar a isonomia no país. Dois quesitos, em particular, chamam a nossa atenção por conta do objeto que ora se discute: no ponto a respeito do trabalho, exige-se a "extensão dos direitos trabalhistas e previdenciários de forma plena às empregadas domésticas e às trabalhadoras rurais" $\left(3^{\circ}\right)$, mas, logo abaixo no inciso $11^{\circ}$, defende-se “Extensão dos direitos previdenciários dos trabalhadores urbanos aos trabalhadores rurais, homens e mulheres".

Assim, a carta, de uma forma ou de outra, acaba por expressar a discriminação que a Constituição de 1988 referendaria no que diz respeito ao direito positi- 
vo em relação ao trabalhado doméstico. Ou seja, equiparou-se os direitos trabalhistas e previdenciários dos trabalhadores rurais ao dos trabalhadores urbanos (Art. 7), estendendo-lhes as disposições consagradas na Consolidação das Leis Trabalhistas (CLT) aliadas às relativas à Previdência social (Seção III), mas o mesmo não se deu com relação às empregadas domésticas.

Consoante à própria autora da pesquisa pioneira sobre a participação das mulheres na Constituinte supracitada, nessa longa caminhada de lutas "nem tudo são flores” e pontos tais quais a reivindicação da extensão de amplos direitos para as empregadas domésticas, dentre outros, não foram "corajosa e suficientemente enfrentados por parlamentares, juristas e movimentos sociais" (SILVA, 2012, p. 5). De fato, foram muitos os avanços da Constituição de 1988 no âmbito dos direitos trabalhistas, mas nem todos foram garantidos a todas as categorias de trabalhadores e trabalhadoras no Brasil.

Poucos direitos concernentes à categoria das domésticas expressaram-se na Constituição - 9 incisos, em relação a 34 reservadas às demais. 0 movimento de empregadas compreende que houve avanços importantes, mas aponta desde o início para as inúmeras insuficiências em relação ao reconhecimento da categoria, diante da mobilização empreendida entre os anos 1987-1988. Conforme Judith Karine Cavalcanti Santos (2010, p. 4):

Aproximadamente 300 representantes da categoria foram a Brasília protocolar formalmente suas demandas na Constituinte, sendo acolhidas na Subcomissão dos Direitos dos Trabalhadores e Servidores Públicos. Este primeiro contato teve resultado positivo com a inclusão da categoria no texto que seria proposto à plenária. Somente depois dos jogos políticos internos à Constituinte, houve cortes na proposta de forma a excluir as trabalhadoras domésticas da proteção integral aos direitos trabalhistas.

Paralelo ao discurso oficial traduzido nas atas da ANC, as trabalhadoras que participaram da caravana à Brasília guardam recordações sobre as dificuldades para a mobilização e a precária estadia na capital brasileira. Creuza Oliveira, trabalhadora doméstica da Bahia, lembra que ficaram em uma creche sem condições de higiene necessárias para uma boa hospedagem.
Em um documento denominado "CONSTITUINTE PRA VALER TEM QUE TERPALAVRA DE MULHER. ERA A PALAVRA DE ORDEM DAS MULHERES", no qual faz um balanço sobre os 20 anos da Constituição em 2008, a então Presidente de honra do Sindicato das(os) trabalhadoras/es Domésticas (os) da área Metropolitana do Recife - PE, Lenira Maria de Carvalho, conta um pouco de como foi o processo de preparação das empregadas para a participação política ativa no processo de construção da Carta Magna de 1988:

\begin{abstract}
Enquanto os constituintes discutiam como seria a constituição de 1988, movimentos populares incluindo a associação das trabalhadoras domésticas (hoje sindicato) formaram uma grande constituinte discutindo suas propostas para fazerem parte da constituição, isso durou 2 anos, na sede da ação católica operária em Recife - PE. Tínhamos reuniões de 15 em 15 dias, era muita discussão, as vezes participava um advogado para esclarecimento. Fizemos um seminário, para entendermos o que era constituinte, depois realizamos um ato público em frente ao teatro Santa Izabel em Recife- PE, para chamar a atenção da sociedade, para o grande acontecimento que seria realizado em outubro de 1988. A nova Constituição para nós trabalhadoras domésticas foi um grande aprendizado, junto com os movimentos populares e de mulheres. [...]. Com a associação de trabalhadoras domésticas, fizemos seminários, junto com a associação de João Pessoa onde discutimos as propostas específicas que falava dos direitos trabalhistas. A gente não sabia o que era Constituição e Constituinte, era convidado um advogado para explicar. (ex.. Partíamos das nossas assembleias e nosso estatuto, daí comparávamos a Assembléia Constituinte e com a Constituição). Era uma grande Democracia, onde se juntava vários movimentos para ver o que era comum, e o que era específico, como no nosso caso que era os direitos trabalhistas. (ex: para conseguirmos ônibus para ir à Brasília, era o conjunto tirado em comissão). Foi muito lindo, todos os movimentos populares, no dia em que fomos a Brasília entregar as propostas escritas com o grande número de assinaturas. Em outro momento, fomos todas as trabalhadoras domésticas do Brasil, entregar nossas propostas, nas mãos do Dr. Ulysses Guimarães, já que não tínhamos conseguido as 30 mil assinaturas das domésticas. Tivemos uma grande aliada, a então Deputada Benedita da Silva do PT, e outras deputadas de partidos diferentes, que se uniram nas propostas das mulheres, e também houve ajuda do Conselho Nacional dos Diretos das Mulheres. Não conseguimos
\end{abstract}


tudo o que queríamos, mas fomos reconhecidas como categoria profissional, e então fundamos o nosso sindicato. (SILVA, 2012, p. 142)

Por fim, o depoimento de Creuza Oliveira, liderança negra e ex-presidente da Federação Nacional das Trabalhadoras Domésticas, colhido pela mencionada pesquisadora, serve de exemplo das dificuldades encontradas pelas trabalhadoras domésticas no período para conseguirem encaminhar as suas demandas no processo de Constituinte - sobretudo, ressalta Santos (2010, p. 4), por tratar-se de relato inviabilizado nas narrativas oficiais a respeito da ocasião:

Queriam nos impedir de entrar no Parlamento pra falar com Ulysses Guimarães. Se não fosse a nossa grande parceira Benedita da Silva, a gente não tinha entrado. Eu lembro de Amália, de Recife, queria ir pro braço, quebrar o vidro, porque fecharam as portas, colocaram seguranças. [...]. Chegou nos tapetes vermelhos a gente acampou. E foi uma das maiores categorias [...] e os meios de comunicação não noticiaram essas coisas, as nossas idas e vindas pra conseguir que na Constituição Federal a gente conquistasse os direitos. Quando o Presidente da câmara nos recebeu, ele veio com o discurso de que ele tinha uma trabalhadora doméstica, com mais de 30 anos na casa dele e que era como se fosse da família. Eu lembro que a companheira Lenira [...] quando pegou o microfone disse a ele "Nós não queremos ser da família. Nós queremos que o senhor reconheça o nosso valor. Na hora de votar nos nossos direitos, levante o crachá a favor" (Oficina Nacional das Trabalhadoras Domésticas: Construindo o Trabalho Decente. Brasília. 22 de agosto de 2009. Gravação da autora.)

\section{OS DIREITOS DAS DOMÉSTICAS POSITIVADOS NA CONSTITUIÇÃO}

Após mais de um ano na redação da Constituição, realização de amplas consultas a especialistas e setores organizados e representativos da sociedade, a Assembleia Nacional Constituinte promulgou, em 5 de outubro de 1988, a Carta considerada mais democrática da história brasileira, denominada de "Cidadã". Mas, de fato, nos resta questionar se essa alcunha é válida para todas e todos trabalhadores brasileiros, isto é, se a cidadania propagada foi garantida a toda sociedade em sua plenitude.

No que tange aos trabalhadores urbanos e rurais, houve significativos avanços em pautas desde muito requeridas pelos sindicatos e enfim positivadas pela Constituição: a jornada de trabalho foi estabelecida em 44 horas semanais (Art. $7^{\circ}, \mathrm{XIII}$ ) - conquanto em países industrializados mais avançados, como a Alemanha já se luta por 36 horas; na França, isso já é realidade. Universalizou-se e garantiu-se o direito de greve, inclusive dos funcionários públicos. Além de estender a licença maternidade para 120 dias, criouse a licença paternidade de 5 dias; transformou-se as demissões, ao tentar crias garantias ao empregado, em um ônus para o empregador ao determinada o pagamento de uma multa de $40 \%$ sobre o valor do Fundo de Garantia por Tempo de Serviço (FGTS) por demissões imotivadas; previu-se o adicional de 50\% sobre as horas extraordinárias, anteriormente definidas em $20 \%$ (Art. $7, \mathrm{XVI}$ ), dentre outros.

Outrossim, a Carta de 1988 trouxe mudança importante no que tange a questão de saúde da classe trabaIhadora a qual não contemplou a doméstica: o Art. $7^{\circ}$ instituiu o seguro contra acidentes de trabalho, sob responsabilidade do empregador, sem excluir a indenização a qual está obrigado a pagar, mesmo no caso de inexistir dolo - for caso de "culpa", como se diz no Direito Penal. Afora a integração da saúde do trabalhador no Sistema Único de Saúde (SUS) para todos.

No rol de direitos estendidos às empregadas domésticas, o parágrafo único do mesmo artigo (Art. $7^{\circ}$ ) passou a assegurar além daqueles prévios a Constituição, os relativos aos incisos IV, VI, VIII, XV, XVII, XVIII, XIX, e XXIV, ou seja, direito ao salário mínimo, à irredutibilidade salarial, ao décimo terceiro salário, ao repouso semanal remunerado, preferencialmente aos domingos, ao gozo de férias remuneradas anuais, com acréscimo remuneratório de pelo menos um terço do salário normal, licença à gestante, sem prejuízo de emprego e salário, com duração de cento e vinte dias, licença-paternidade, nos termos legalmente assegurados, aviso prévio proporcional ao tempo de ser- 
viço, de no mínimo trinta dias e aposentadoria, além da integração à previdência social.

Ora, diante de tanta resistência em positivar a equiparação dos direitos das trabalhadoras domésticas ao dos trabalhadores urbanos e rurais, movimento organizado das domésticas, tal qual outras categorias profissionais e segmentos da sociedade, produziu uma carta para os parlamentares, expressando o desejo de reconhecimento pleno da cidadania que veria ser dispensado à categoria. Convém reproduzir ipsis litteris o conteúdo desse documento, pela importância de síntese histórica acerca das lutas dessas mulheres, mas também como bandeira a ser discutida no contexto da construção da Proposta de Emenda Constitucional $n^{0} 72$ e, infelizmente porquanto ainda não efetivada em sua integralidade:

Carta das Trabalhadoras Domésticas aos Parlamentares Constituintes - Maio de 1987

Exmos Srs. Deputados Federais e Senadores Constituintes Nós, Trabalhadoras Domésticas, representantes de vinte e três Associações, de nove Estados do Brasil, reunidas em Nova Iguaçu (RJ), em 18 e 19 de abril de 1987, elaboramos este documento, que resume nossas principais reivindicações. Somos a categoria mais numerosa de mulheres que trabalham neste país, cerca de $1 / 4$ (um quarto) da mão-de-obra feminina, segundo os dados do V Congresso Nacional de Empregadas Domésticas, de janeiro de 1985. Fala-se muito que os trabalhadores não produzem lucro, como se lucro fosse algo que se expressasse, apenas e tão somente, em forma monetária.

Nós produzimos saúde, limpeza, boa alimentação e segurança para milhões de pessoas. Nós, sem termos acesso à instrução e cultura, em muitos casos, garantimos a educação dos filhos dos patrões. Queremos ser reconhecidos como categoria profissional de trabalhadores domésticos e termos direitos de sindicalização, com autonomia sindical. Reivindicamos o salário mínimo real, jornada de 40 (quarenta) horas semanais, descanso semanal remunerado, $13^{\circ}$ salário, estabilidade após 10 (dez) anos no emprego ou FGTS (Fundo de Garantia por Tempo de Serviço) e demais direitos trabalhistas consolidados. Extensão, de forma plena, aos trabalhadores domésticos, dos direitos previdenciários consolidados. Proibição da exploração do trabalho do menor com pretexto de criação e educação. Que o menor seja respeitado em sua integridade física, moral e mental. Entendemos que toda pessoa que exerce trabalho remunerado e vive desse trabalho é trabalhador e consequentemente, está submetido às leis trabalhistas e previdenciárias consolidadas. Como cidadãs e cidadãos que somos, uma vez que exercemos o direito de cidadania, através do voto direto, queremos nossos direitos assegurados na nova Constituição" (APED, maio de 1987).

A despeito de proclamar a igualdade jurídica entre homens e mulheres, de todos perante a lei "sem distinção de qualquer natureza” (Art. $5^{\circ}$ ), a Constituição alijou a categoria das domésticas de importantes conquistas garantidas aos trabalhadores urbanos e rurais. Proteção contra despedida sem justa causa, seguro desemprego, FGTS, salário-família, regulamentação da jornada de trabalho, hora extra, são exemplos de direitos importantes não garantidos em sede constitucional em 1988.

Ao arrepio dos próprios princípios, a Norma Maior perpetuou a discriminação desde sempre dispensada a um grupo social marcado pelas mazelas dos sistemas de dominação racismo, patriarcado e capitalismo. Ou seja, foi de encontro ao que deveria ser o seu mandamento último: a erradicação tanto das desigualdades quanto às violações a dignidade da pessoa humana, da qual as domésticas padecem enquanto vulneraríeis socioeconômicas.

Nesse cenário, não há a tão propagada “justiça social” em suas letras prolatadas. A Constituição dita "Cidadã", se por um lado tirou as empregadas domésticas do limbo no qual se encontravam em termos de direitos formais garantidos pelo ordenamento jurídico brasileiro, destinou-lhes normas como apêndice dos direitos amplos e gerais dos trabalhadores urbanos e rurais, impedindo o acesso a direitos trabalhistas fundamentais. Data vênia, a Constituição simplesmente postergou no tempo os efeitos sociais, econômicos, e jurídicos da gênese escravocrata do trabalho doméstico, quase incólume durante todo século XX.

\section{CONTRADICÕES E POTENCIALIDADES DECOR- RENTES DA CF/88}

De forma alguma se ignora nem se pretende negar a importância dos avanços trazidos pela Constituição Federal de 1988. Eles significaram, sem som- 
bra de dúvidas, um grande marco na consolidação de direitos sociais em nosso ordenamento jurídico. Como ressalta o eminente constitucionalista Paulo Bonavides (2011, p. 374):

\begin{abstract}
No tocante aos direitos sociais básicos, a Constituição define princípios fundamentais, como os valores sociais do trabalho e a livre iniciativa; estabelece objetivos fundamentais para a república como o desenvolvimento nacional, a erradicação da pobreza e a marginalização e a redução das desigualdades sociais e regionais e, enunciam os direitos sociais, abrangendo genericamente a educação, a saúde, o trabalho, o lazer, a segurança, a previdência social, a proteção à maternidade e à infância, a assistência aos desempregados. [...] com o se vê, o novo texto constitucional imprime uma latitude sem precedentes aos direitos sociais básicos, dotados agora de uma substantividade nunca antes conhecida nas Constituições anteriores. (BONAVIDES, 2011, p. 374).
\end{abstract}

Por essas razões apontadas pelo constitucionalista, a Carta Magna foi desde logo cognominada de "cidadã”. Afinal, houve a restauração dos direitos políticos, a instauração de uma série de direitos sociais até então inexistentes (garantida de saúde e educação públicas universais, proteção à maternidade e à infância, assistência aos desamparados etc. Houve a assim chamada "constitucionalização" de direitos trabalhistas, com uma inédita catalogação de direitos aos trabalhadores previstos na Constituição e mesmo a domésticas foram consideradas categoria profissional, como bem lembrou a liderança sindical em seu depoimento.

A Constituição, de maneira contraditória, instaurou uma ordem paradigmática em relação aos direitos fundamentais tanto dos trabalhadores quanto de todo e qualquer ser humano que, na prática, possibilitou uma abertura para interpretações que pudessem beneficiar as empregadas domésticas. Suas reivindicações foram aumentando e chegavam ao foro trabalhista demandas para pagamento de FGTS, indenização de seguro-desemprego, horas extraordinárias, adicional noturno, férias de 30 dias e multa pelo atraso no pagamento das verbas rescisórias, sob o argumento de que a Constituição Federal, no capítulo dos direitos e garantias fundamentais, pre- via a não discriminação e o valor social do trabalho e a dignidade da pessoa humana.

Com estes argumentos, várias decisões judiciais estendiam à categoria das domésticas direitos não assegurados especificamente pela legislação, à luz dos princípios constitucionais (principalmente o da igualdade). Nesse sentido, há algumas decisões que garantiram direitos não previstos expressamente no rol elencado pela Carta Magna, como a seguinte:

EMPREGADO DOMÉSTICO. HORAS EXTRAS. LIMITE DE JORNADA EXPRESSAMENTE CONTRATADO. DEFERIMENTO.

0 art. $\underline{70}^{\circ}$, parágrafo único, da Carta Magna elenca os direitos sociais dos trabalhadores urbanos e rurais extensivos aos empregados domésticos, não estando dentre eles a limitação da jornada semanal de trabatho. Contudo, podendo as partes avençar tudo aquilo que não é vedado em lei (Cód. Civil/1916, art. 82; Cód. Civil/2002, art. 104, II) e tendo em vista a obrigação de observar-se que o avençado pelas partes deve ser cumprido - pacta sunt servanda - não há como negar-se ao autor a pretensão de recebimento de horas extras porque estabelecido, em contrato celebrado livremente entre ele e o reclamado, o horário de trabatho que deveria ser cumprido. CONFISSÃO. INTERPRETAÇÃO RESTRITA. Não correspondendo a confissão judicial real, via de regra, à integra do interrogatório, os termos da declaração da parte confidente devem ser tomados sem alargamento de sentido ou alcance. Recurso conhecido e parcialmente provido (TRT-10 $3^{a}$ Turma ROPS 793200401610000 DF 00793-2004-01610-00-0. Relatoria: Juiz Antonio de Umberto de Souza Júnior, julgado em 09/12/2004).

Todavia, na discussão sobre o caráter do rol de direitos assegurados a tal classe obreira estampado na Carta Magna - se meramente exemplificativo ou taxativo, Maurício Goldinho Delgado (2005, p. 379) aduz que "a posição hermenêutica hoje dominante que no instante em que a carta de 1988 pretendeu se referir e englobar em suas normas a categoria doméstica fê-lo expressa e topicamente" no parágrafo único do art. $7^{\circ}$. Em sendo assim, continua, "descaberia produzir-se interpretação extensiva onde a constituição conferiu tratamento restrito e excepcional". Esse é o argumento que sustenta a maioria dos julgados, tal qual o baixo referido, in verbis: 
AGRAVO DE INSTRUMENTO. EMPREGADO DOMÉSTICO. HORAS EXTRAS. 1. 0 art. $7^{\circ}$ da Constituição Federal, em seu parágrafo único, não oferece aos trabalhadores domésticos o resguardo dos incisos XIII e XVI, assim não thes assegurando o direito à jornada limitada e às horas extras. Tais títulos também não encontram previsão na legislação ordinária (Lei n. 5.859/72). 2. A despeito das condições atípicas em que se dá o seu ofício, com a natural dificuldade de controle e de atendimento aos direitos normalmente assegurados aos trabalhadores urbanos, não há dúvidas de que a legislação é tímida em relação aos empregados domésticos, renegando thes determinadas garantias necessárias à preservação de sua dignidade profissional (CF, art. $\left.1^{\circ}, \mathrm{III}\right)$. 3. Esta certeza, no entanto, não autoriza, no plano judicial, a superação das fronteiras estabelecidas pelas normas vigentes, de forma a se compelir o empregador ao adimplemento de obrigação que o ordenamento jurídico não the impõe. É impossível o deferimento de horas extras ao empregado doméstico. Agravo de instrumento conhecido e desprovido. (TST, AIRR 810/2001-002-17-00. PUBLICAÇÃO: DJ -23/06/2006. Relator: Ministro Alberto Bresciani).

O doutrinador Amauri Mascaro Nascimento (1991, p. 76) comenta que o objetivo inicial da Assembleia Nacional constituinte seria equiparar integralmente os direitos conferidos aos trabalhadores domésticos e aos demais, mas que ao longo dos trabalhos constataram-se "incompatibilidades”, razão pela qual se restringiu a gama de garantias dos domésticos:

Desde o início dos trabalhos da Assembleia Nacional Constituinte, através das primeiras propostas, notou-se uma tendência no sentido da inclusão do empregado doméstico dentre aqueles que mereciam uma atenção especial, e, nos primeiros projetos que foram apresentados, pretendia-se a total equiparação de direitos entre domésticos, trabalhadores de empresas rurais, urbanos e funcionários públicos. Na medida em que as discussões parlamentares se desenvolveram nas diversas comissões, foram modificadas as propostas, com a exclusão de direitos que realmente eram incompatíveis com a natureza desse trabalho, até que se chegou a uma formula aprovada pela Comissão de Sistematização e que assegurou ao doméstico alguns dos direitos previstos na Constituição para o trabalhador urbano em geral e que são os indicados no art. $7^{\circ}$., § $2^{\circ}$. (NASCIMENTO, 1991, p. 76).

A partir das "especificidades" da natureza do trabalho doméstico, justifica-se a discriminação de tra- tamento na regulação empreendida de modo tal que resta legítimo não lhes assegurar todos os direitos conquistados pelos demais setores da classe obreira (urbana e rural). Com isso a doutrina e jurisprudência dominantes legitimarão um conjunto de decisões desfavoráveis à categoria.

\section{CONCLUSÃO}

Ao invés de tratar os desiguais conforme as suas desigualdades a fim de possibilitar a equiparação de condições, o legislador constitucional de 1988 concebeu dispositivos específicos que vão de encontro com a lógica sistêmica da Constituição, colocando as empregadas domésticas num patamar ainda mais distante dos demais empregados. Entretanto, será utilizando o discurso jurídico que atravessa a Constituição que os movimentos sociais em geral e das empregadas domésticas, em especial, irão pautar a equiparação de direitos.

Ou seja, por um lado trata-se de não esquecer que os legisladores originários alçaram a nível constitucional a perpetuação das discriminações em relação as empregadas domésticas. Antes disso, não havia previsão legal consistente em torno da regulação de tal categoria, também não existia previsão considerada taxativa em termos de direitos na constituição que pudessem ser interpretados restritivamente, isso numa sociedade cuja carga da herança escravocrata patriarcal é tão pesada como a brasileira.

Por outro lado, é preciso ressaltar esse aspecto paradoxal colocado pelos novos paradigmas estabelecidos pela Constituição, qual seja, a possibilidade de se lutar por mais direitos a partir dos seus princípios. Com efeito, A Carta Magna foi fruto de muita luta política dos movimentos sociais e forças progressistas contra a hegemonia do poder econômico e político dominantes da sociedade brasileira ${ }^{1}$.

\footnotetext{
1 Há alguns documentários e reportagens que mostram como os movimentos sociais e partidos de esquerda conseguiram encaminhar e ver aprovadas pautas progressistas, transformando a constituição num documento considerado nitidamente socialdemocrata, em que pese algumas contradições. Para ficar num exemplo: como era ano de eleição municipal, as centrais sindicais penduraram outdoors pelas cidades de origem dos par-
} 
Nessa esteira, as trabalhadoras domésticas lutaram pela equiparação de direitos e em 2013, enfim, conquistaram a aprovação de uma Proposta de Emenda Constitucional (PEC) (a PEC 72) que visou em larga medida equiparar os seus direitos aos dos demais setores da classe trabalhadora garantidos pela Constituição. Logo, pode-se afirmar que tal marco constitucional, com todas as contradições, constituiu-se enquanto um divisor de águas importante na história de lutas dessas trabalhadoras, a partir do qual se pôde sustentar um discurso para a garantia crescente de mais e mais direitos que culminou com a implementação da chamada PEC das domésticas em 2015, no governo Dilma.

Diante de uma série de retrocessos ocorridos logo nos momentos posteriores à Constituinte e que se intensificaram nos governos FHC, Lula e Dilma, cabe ressaltar a importância da $\mathrm{CF} / 88$, no que de muito ela contribuiu para os movimentos sociais em termos de direitos e garantias. Discute-se as suas limitações não para pôr abaixo um conjunto de avanços conquistados por diversos setores organizados, mas para potencializar os pontos que são caros a todos e todas que lutam pelos direitos sociais e humanos, contra qualquer forma de desigualdade e discriminação social e a favor dos princípios constitucionais que constituem as bases do estado democrático de direito.

Nesse sentido, as diversas medidas adotadas no período do governo de Michel Temer, especialmente a reforma trabalhista, só asseveram ainda mais uma situação em que os direitos e princípios garantidos na Constituição restam cada vez mais comprometidos. Por isso, nos cabe, nesses 30 anos da CF/88, lembrar da importância desse momento histórico em que a Constituinte se deu, refletindo toda sua complexidade, limites e potências, celebrando as possibilidades advindas desse processo, para que não se possa coadunar com retrocessos que nos faça retornar a um estado social anterior àquele estabelecido pela Constituicão de 1988

lamentares que votassem contra emendas e propostas populares, de modo que muitos desses parlamentares conservadores, por motivos puramente eleitoreiros, barganharam com os representantes dos partidos de esquerda na Constituinte a aprovação das propostas, a fim de não sofrer derrota nas eleições (Link documentário sobre a Constituinte: https://www.youtube. com/watch?v=Nc-1GIZD1t0. Acesso em 20/10/2016).

\section{REFERÊNCIAS}

ABRAMO, Laís. A Constituição de 1988 e o mundo do trabalho no Brasil. In: KREIN, José Dari; SANTANA, Marco Aurélio; BIAVASCHI, Magda Barros. Vinte anos da Constituição Cidadã no Brasil. São Paulo: LTr, 2010.

ALENCAR, Chico et al. História da sociedade brasileira. 13. ed. Rio de Janeiro: Ao Livro Técnico, 1996.

BARDIN, L. Análise de conteúdo. Lisboa: Edições 70, 2006.

\section{BERNARDINO-COSTA, Joaze. Sindicatos das}

trabalhadoras domésticas no Brasil: teorias da descolonização e saberes subalternos. 2007. Tese (Doutorado) - Universidade de Brasília, Brasília, 2007.

\section{BIAVASCHI, Magda Barros. Os direitos das}

trabalhadoras domésticas e as dificuldades de implementação no Brasil: contradições e tensões sociais. São Paulo: Friedrich Ebert Stiftung (FES), 2014.

BONAVIDES, Paulo. Curso de direito constitucional. 26. ed. São Paulo: Malheiros, 2011.

BRASIL. Consolidação das Leis do Trabalho. Decretolei $\mathbf{n}^{0} \mathbf{5 . 4 5 2}$, de $1^{\circ}$ de maio de 1943 . Obra coletiva de autoria da Editora Saraiva com a colaboração de Antônio Luiz de Toledo Pinto, Márcia Cristina Vaz dos Santos Windt e Lívia Céspedes. 32. ed. São Paulo: Saraiva, 2005.

\section{BRASIL. Constituição (1988). Constituição da}

República Federativa do Brasil. Obra coletiva de autoria da Editora Saraiva com a colaboração de Antonio Luiz de Toledo Pinto, Márcia Cristina Vaz dos Santos Windt e Lívia Céspedes. 35. ed. São Paulo: Saraiva, 2005.

CORDEIRO, Roberto Benavente. Dos direitos do empregado doméstico. Incoerência da interpretação restritiva em face do conteúdo principiológico 
constitucional. Revista do Departamento de Direito do Trabalho e da Seguridade Social da USP, São

Paulo, v. 2, n. 3, p. 173-231. jan./jun. 2007.

DELGADO, Maurício Godinho. Curso de direito do

trabalho. 4. ed. São Paulo: LTr, 2005.

\section{MAZIEIRO, Luís Guilherme Soares. Direitos}

fundamentais e discriminação de gênero: ausência de direitos e proteção ao trabalho doméstico. 2010. 156f. Dissertação (Mestrado em Direito) - Universidade Metodista de Piracicaba, Piracicaba, 2010.

MELLO, Celso Antonio Bandeira de. Conteúdo jurídico do princípio da igualdade. 3. ed. São Paulo: Malheiros, 2003.

MELO, Hildete Pereira de. 0 serviço doméstico remunerado no Brasil: de criadas a trabalhadoras. Texto para discussão nº 565 IPEA. Rio de Janeiro 1998.

NASCIMENTO, Amauri Mascaro. Direito do Trabalho na Constituição de 1988. 2. ed. São Paulo: Saraiva, 1991.

REIS FILHO, Daniel Aarão (coord.). Modernização, ditadura e democracia (1964-2010). Rio de Janeiro:

Objetiva, 2014. (História do Brasil Nação: 1808-2010; v. 5).
REIS FILHO, Daniel Aarão. Ditadura e democracia no Brasil: do golpe de 1964 à Constituição de 1988. Zahar Editora, 2014.

\section{SAFFIOTI, Heleieth. Emprego doméstico e}

capitalismo. Petrópolis, RJ: Vozes, 1979.

SANTOS, Judith Karine Cavalcanti. Participação das trabalhadoras domésticas no cenário político brasileiro. Congresso: Fazendo Gênero 9: Diásporas, Diversidades, Deslocamentos.

SILVA, Salete Maria da. A carta que elas escreveram: a participação das mulheres no processo de elaboração da Constituição Federal de 1988. 2012. 320f. Tese. (Doutorado em Estudos Interdisciplinares sobre Mulheres, Gênero e Feminismo) - Faculdade de Filosofia e Ciências Humanas, UFBA, Salvador, 2012.

\section{SOARES, L. R. P.; SOUZA, J. A. As recentes} modificações do contrato de emprego doméstico: EC 72/2013 - O que está em vigor e o que ainda está pendente de regulamentação. 
